\title{
A FILOSOFIA E SEUS OUTROS: ENTUSIASMO E FANATISMO NOS SÉCULOS 17 E 18
}

\author{
Felipe Aquino de Cordova ${ }^{1}$ \\ Universidade Federal do Paraná (UFPR) \\ (iD) https://orcid.org/0000-0003-3719-5852 \\ E-mail: felipeacordova@gmail.com
}

\section{RESUMO:}

As noções de entusiasmo e fanatismo, por sobre estarem associadas ao fenômeno concreto do fervor religioso à época da Reforma, foram também, ao longo dos séculos 17 e 18, o objeto de uma literatura que construiu uma imagem específica dos assim chamados entusiastas, fossem eles os puritanos ingleses, os profetas huguenotes ou os convulsionários jansenistas. Ao construir essa imagem, a literatura - filosófica, médica ou satírica - produziu ao mesmo tempo a imagem especular de si mesma, ora como pura alteridade em relação ao fanático, ora relativizando essa oposição. Nosso percurso parte de algumas dessas formulações na Inglaterra do início do século 17 para, em seguida, se deter com mais demora nas elaborações de Swift e Diderot acerca do fanatismo e do entusiasmo, de início a meados do século XVIII, mostrando que a própria filosofia, frequentemente entendida como o avesso do fanatismo ou da loucura, pode também converter-se em seu outro quando cede ao entusiasmo.

PALAVRAS-CHAVE: Entusiasmo; Fanatismo; Sátira; Iluminismo.

\section{PHILOSOPHY AND ITS OTHERS: ENTHUSIASM AND FANATICISM IN THE 17th AND 18th CENTURIES}

\begin{abstract}
:
The notions of enthusiasm and fanaticism, besides the fact that they were associated with the concrete phenomenon of religious zeal at the time of the Reformation, were also, throughout the 17th and 18th centuries, the object of a literature that built a specific image of the so-called enthusiasts, be they the English Puritans, the Huguenot prophets or the Jansenist convulsionaries. By constructing this image, literature - philosophical, medical or satirical - produced at the same time the specular image of itself, sometimes as pure alterity in relation to the fanatic, sometimes relativizing this opposition. Our journey starts from some of these formulations in England at the beginning of the 17th century, and then pays attention carefully to the elaborations of Swift and Diderot about fanaticism and enthusiasm, from the beginning to the middle of the 18th century, showing that philosophy itself, often understood as the opposite of fanaticism or madness, can also become its other when it gives in to enthusiasm.
\end{abstract}

KEYWORDS: Enthusiasm; Fanaticism; Satire; Enlightenment

\footnotetext{
${ }^{1}$ Doutorando(a) em Filosofia na Universidade Federal do Paraná (UFPR), Curitiba - PR, Brasil.
} 


\section{Representações do dissidente puritano}

As noções de entusiasmo e fanatismo, por sobre estarem associadas ao fenômeno concreto do fervor religioso à época da Reforma, foram também, ao longo dos séculos 17 e 18, o objeto de uma literatura que construiu uma imagem específica dos assim chamados entusiastas, fossem eles os puritanos ingleses, os profetas huguenotes ou os convulsionários jansenistas. Ao construir essa imagem, a literatura - filosófica, médica ou satírica - produziu ao mesmo tempo a imagem especular de si mesma, ora como pura alteridade em relação ao fanático, ora relativizando essa oposição.

Na Inglaterra, a sátira que ridiculariza o fervor religioso remonta ao período isabelino (1558-1603), e se prolifera nas eras jacobina (1603-1625) e carolina (1625-1642), através de satiristas como Thomas Middleton, John Fletcher e Ben Jonson. Os puritanos eram atacados nos palcos em parte devido ao fato de que qualquer dissidência religiosa era vista com desconfiança, em vista da memória recente de conflitos violentos por toda a Europa, mas sobretudo porque os puritanos foram desde sempre ferrenhos opositores do teatro público. ${ }^{2}$ Quaisquer que fossem as razões, contudo, as primeiras representações do puritano no teatro inglês são marcadamente caricaturais, e acentuam especialmente dois caracteres: a hipocrisia e a ignorância. Zeal-of-the-land Busy, o puritano de Jonson em Bartholomew Fair (1614), por exemplo, é retratado como um hipócrita que se utiliza de subterfúgios para justificar sua ida à feira, onde, aliás, são encenadas as peças que ele condena. ${ }^{3}$ Ao longo de todo o século estará presente, mais ou menos nuançada, esta dupla caricatura: ou o puritano é um hipócrita que finge uma inspiração divina para alcançar objetivos inconfessos, ou é um indivíduo ignorante, em geral pertencente às classes baixas, que, facilmente ludibriado pelos clérigos puritanos, adere inocentemente ao entusiasmo.

A sátira não foi, contudo, o único discurso a forjar a imagem do puritano e do entusiasta no século 17; um discurso médico concorrerá também para moldá-la, e acabará, por sua vez, incidindo sobre a própria sátira. Enquanto esta, num primeiro momento, se contentava em pintar a caricatura do entusiasta e ridicularizar suas características externas, uma certa literatura buscará apontar as causas do fenômeno do entusiasmo e do fanatismo, e encontrará essa explicação nos fatores fisiológicos. Nesse sentido, a Anatomia da Melancolia (1621) de Robert Burton é provavelmente a primeira elaboração analítica sobre as causas do entusiasmo. Burton o associará a uma teoria dos humores e procederá à sua análise psicológica.

A obra monumental de Burton aborda o tema do entusiasmo em sua terceira partição, dedicada à melancolia amorosa, à melancolia heroica, ao ciúme, e à melancolia religiosa. Esta última é o tema da quarta e última seção da partição. Num primeiro momento, a abordagem do entusiasmo em A Anatomia da Melancolia repisa o lugar-comum da tradição satírica inglesa do século 17. A adesão sincera ao entusiasmo seria consequência da estupidez, de limitações cognitivas, enquanto que os entusiastas de nível intelectual mais elevado não passariam de

20 termo 'puritano' designava na Inglaterra do séc. 17 os vários grupos protestantes que desde o século 16 advogavam uma radicalização da Reforma naquele país; acreditavam que a Igreja da Inglaterra não havia se 'purificado' suficientemente das práticas católicas romanas. Embora fossem muitas vezes referidos como dissidentes, surgiram e inicialmente se mantiveram, em sua maioria, no interior da Igreja. Após uma ascensão ao poder via Parlamento e Cromwell durante o Commonwealth, em consequência da Guerra Civil (1642-1646), seriam forçados a uma dissidência expressiva pelo "Grande expurgo" que se seguiu à Restauração de 1660, quando muitos partiram para as colônias inglesas na América. Os clérigos que ainda assim continuaram seus ministérios, fizeram-no clandestinamente até 1689, quando o Ato de Tolerância promulgado na esteira da Revolução Gloriosa reconheceu novamente a legitimidade de seus credos, agora oficialmente dissociados da Igreja da Inglaterra (Quakers, Anabatistas, Presbiterianos, etc).

30 título da peça de Jonson indica o cenário em que a ação transcorre: a feira de São Bartolomeu, que existiu de 1133 a 1855 , e foi uma das maiores feiras de rua de Londres, unindo comércio e manifestações artísticas. O puritano Busy, ao adentrar a cena II do $3^{\circ}$ ato, refere-se a ela nos seguintes termos: "The wares are the wares of devils, and the whole Fair is the shop of Satan!". Ele comparecerá à feira sob o pretexto de denunciar suas iniquidades, mas logo ficaremos sabendo que sua real intenção era empanturrar-se da carne de porco que era aí servida (Cf. Ben Jonson, 1989, pp. 210-212). 
hipócritas. Em seguida, todavia, Burton aponta as causas fisiológicas dos sintomas da melancolia religiosa (entusiasmo, visões, profecias, etc):

jamais qualquer estranha ilusão de demônios entre eremitas, monges; jamais qualquer visão, fantasmas, aparições, entusiasmos, profetas, quaisquer revelações se passaram sem que o jejum imoderado, a má dieta, a enfermidade, a melancolia, a solidão ou algo do gênero fosse a causa precedente, seu precursor ou concomitante (BURTON, p. 1014).

Outras explicações de natureza fisiológica para o entusiasmo se seguiram à de Burton. Thomas Browne, em sua Pseudodoxia Epidemica (1646), se apega principalmente à ignorância como causa do entusiasmo, mas dá indicações de uma 'psicologia de massas', segundo a qual as imperfeições do indivíduo se tornam erro completo quando os indivíduos se agrupam, como no caso dos puritanos. Meric Casaubon, em seu A treatise concerning enthusiasm (1655), após repisar a tese da propensão das pessoas comuns à ilusão e à autoilusão, define o entusiasmo como "uma extraordinária, transcendente, mas natural fervência [fervency] ou gestação da alma, do espírito ou do cérebro", cuja causa seria um "calor", um "fogo" (WEBSTER, 1933, p. 1144). Certas condições naturais, então, preparariam o corpo do 'fervoroso' [zealot] para as manifestações extraordinárias do entusiasmo, a despeito de sua vontade. Aquele 'fogo', transcendente e ao mesmo tempo natural, não tem suas causas naturais explicitadas, mas descarta-se sua procedência divina, bem como a hipocrisia ou a simples falha cognitiva do entusiasta.

Por fim, seria interessante recordar ainda o Enthusiasmus Triumphatus (1656), de Henry More, que define o entusiasmo como "nada além do engano de estar inspirado", e desenvolve uma explicação de base fisiológica: a alma está com frequência à mercê dos sentidos e assim como é tocada à sua revelia pelas impressões sensíveis através dos órgãos da sensibilidade, poderá sê-lo também por "fantasmas e impressões, sem sua vontade ou consentimento" (MORE, 1662 , sect. IV, p. 3). More sugere, enfim, que uma das possíveis afecções sensíveis que deflagram na alma a ilusão de uma possessão é de natureza sexual:

O 'espírito' que eleva o entusiasta de maneira tão espetacular nada mais é que a flatulência contida no complexo melancólico, e que ascende do humor hipocondríaco por meio de alguma quentura; esse vapor é incensado até a cabeça e, tendo sido primeiro acionado e motivado e, de algum modo, refinado pelo calor, preenche a mente com imaginação variada, e então acelera e amplia a inventividade, tornando o entusiasta admiravelmente eloquente e fluente, como se estivesse bêbado de um vinho novo, trazido de sua adega particular, que reside na região mais baixa de seu corpo (MORE, 1662, sect. XVII, p. 12).

Haveria, portanto, uma causa natural para o entusiasmo e para o fanatismo, o que não poderia deixar de produzir implicações para a própria sátira, que já não lograria atacar as vítimas de uma condição doentia com a mesma ferocidade com que atacava os estúpidos e os hipócritas. Burton, de sua parte, parecia já estar em alguma medida consciente dessas implicações quando aponta a ambiguidade contida na figura do entusiasta e admite a dificuldade em representá-lo univocamente:

na tentativa de falar desses sintomas, devo rir com Demócrito, ou chorar com Heráclito? São tão ridículos e absurdos por um lado, tão lamentáveis e trágicos por outro; uma cena mista se oferece, tão cheia de erros, e uma promíscua variedade de objetos, que eu não sei de que modo representá-la (BURTON, 2016, p. 1017).

\section{Swift e a penetração da análise fisiológica na sátira}

A penetração da análise fisiológica do entusiasmo na sátira é perceptível, por exemplo, em A tale of a tub (1704), de Jonathan Swift. Trata-se, em linhas gerais, de um conto alegórico 
no qual um pai idoso, em seu leito de morte, reúne seus três filhos gêmeos - que, mais tarde, o leitor saberá se tratar de Peter, Martin e Jack, representando, respectivamente, a Igreja Romana, a Igreja da Inglaterra e os dissidentes puritanos -, presenteia-os com três mantos idênticos (simbolizando sua fé ou prática religiosa) e lhes entrega seu testamento (as sagradas escrituras), no qual estão contidas as instruções quanto ao uso dos mantos.

Muitos eventos transcorrem até que a divergência dos três irmãos quanto aos cuidados com seus mantos leva à ruptura, e Martin e Jack são expulsos por Peter da grande mansão em que estavam instalados, após sofrerem uma série de humilhações. A história que, até aqui, havia sido protagonizada por Peter, centra-se então em Jack, representação alegórica do puritano entusiasta. Quando a sexta seção do conto se inicia, Martin e Jack se encontram desalojados e um pouco desorientados, e tratam de começar a retirar de seus mantos os muitos adereços com que Peter havia lhes convencido a orná-lo, ou seja, iniciam a reforma da igreja. Os dois reformadores, entretanto, lançam-se no empreendimento com espíritos diferentes. Martin se guia pelo testamento do pai; logo percebe que um procedimento muito bruto poderia danificar o manto, e prefere trabalhar com ponderação,

mas seu irmão Jack [...] entrou no assunto com outros pensamentos e um espírito um tanto distinto. A memória dos danos causados por Peter produziu um grau de ódio e despeito muito mais apto a incitá-lo que qualquer preocupação com as instruções paternas; estas lhe pareceram, na melhor das hipóteses, secundárias e subordinadas à primeira. Todavia, ele foi capaz de uma inversão para encontrar um nome muito plausível para essa mistura de humores, honrando-a com o título de fervor [zeal $]$ (SWIFT, 2002, pp. 140-141).

A mistura de humores que compunha o estado de espírito de Jack no momento de reformar seu manto, isto é, de moldar sua fé, incluía como elemento principal o ressentimento em relação aos sofrimentos causados por Peter. Jack se põe a remoer as traições e ultrajes sofridos e, "tendo assim estimulado e inflamado a si mesmo tanto quanto possível, e colocando-se desse modo em um temperamento delicado para iniciar uma reforma, pôs-se a trabalhar imediatamente" (SWIFT, 2002, p. 141). É interessante lembrar que será precisamente esse um dos pontos da crítica de Shaftesbury ao entusiasmo, poucos anos mais tarde, em A letter concerning enthusiasm (1708). A má disposição de humor dos religiosos ao fundarem ou reformarem suas doutrinas; sua sujeição às más paixões ou ao que, pelo menos desde Burton, se chamava de melancolia, é que faria com que a imagem de deus que é então forjada fosse a de um ser igualmente irascível, colérico, vingativo, etc (SHAFTESBURY, 2000, sect. 3, pp. 12-17). Ademais, haveria para Swift uma espécie de simbiose, uma afinidade entre o fervor e o entusiasmo, de um lado, e a ruptura e o radicalismo, de outro: "o fervor nunca é tão aplicável como quando se trata de um rompimento" (SWIFT, 2000, p. 142).

Cabe observar então que aqui já não se trata mais de explorar as características do puritano, pois ele não existe de antemão na alegoria de Swift. Em vez disso, vemos sua gênese a partir de um ressentimento, uma disposição melancólica que funda o puritanismo e aciona a espiral do entusiasmo, que é de tal sorte que precipitará Jack "nas mais bizarras excentricidades já concebidas por um cérebro" (ibid., p. 145). A oitava seção do conto será inteiramente dedicada à seita dos Eolistas, fundada por Jack. $\mathrm{O}$ que é aí ridicularizado são as elucubrações delirantes desses homens que, levados por suas fantasias, se creem transpassados e inspirados por uma espécie de "vento". O Discurso sobre a operação mecânica do espírito, publicado em apêndice ao conto, por sua vez, fornecerá também uma explicação fisiológica para o entusiasmo, remetendo-o, em última instância, a uma corrupção dos sentidos que poderia ter origem natural e em seguida aplicar artifícios, ou, ao contrário, começar pelo artifício e se tornar natural. Por isso as assembleias dos entusiastas incluem uma série de procedimentos rítmicos, de modo a promover uma hipnose. 
Desse modo, a história da tradição satírica inglesa denota certa evolução no sentido de uma sensibilização, uma modulação do riso que tem por objeto o entusiasmo e o fanatismo; ela inicia com uma sátira mais grosseira do puritanismo, que caracterizava - ou, antes, caricaturava - o dissidente sob os estigmas da hipocrisia e da estupidez, e evolui no sentido de um humor aparentemente mais razoável, não estigmatizante de indivíduos ou de grupos determinados. O fanático ou entusiasta, assim, deixa de ser uma alteridade absoluta. A evolução da sátira religiosa na Inglaterra ao longo de um século não levou à sua supressão, não interditou o riso, mas mudou seu objeto e sua abordagem; aquilo de que se ri, e como se ri. Esse processo, como veremos a seguir, é tematizado e ganha novos desdobramentos quando passamos à banda francesa.

\section{Diderot na tradição satírica moderna}

Diderot não escreveu, propriamente falando, uma sátira da religião, mas certas passagens de alguns de seus textos se insinuam nesse sentido, e poderiam ser lidas como tal. É inegável, por exemplo, o tom de sátira religiosa assumido pelas observações de Oru em seu diálogo com o capelão, no Suplemento à Viagem de Bougainville, valendo-se inclusive de linguagem alegórica ao mencionar os três senhores do homem - o grande obreiro, os magistrados e os sacerdotes - para referir as leis natural, civil e divina (DIDEROT, 2000, p. 283). Num tom bastante distinto, ${ }^{4} A$ Religiosa não deixa de apresentar, a seu modo, uma sátira da religião, especialmente se atentarmos para a maneira como são retratadas as madres superioras dos três conventos por que passa Suzanne.

Para o que nos interessa aqui, contudo, será mais produtivo voltar o olhar para um outro texto contendo elementos de sátira religiosa. Trata-se da primeira dentre as três partes que compõem O passeio do cético, de 1747, cujo Discurso Preliminar inscreve a obra na tradição satírica moderna ao comparar seu tom com o "de Bayle, de Montaigne, de Voltaire, de Barclay, de Woolston, de Swift, de Montesquieu" (DIDEROT, 1994, p. 77). É possível reconhecer, com efeito, a herança de Woolston na crítica dos milagres (ibid., p. 95); assim como a semelhança com a comicidade típica das Cartas persas de Montesquieu, quando o olhar artificialmente ingênuo do narrador d'O passeio parece colocá-lo em posição análoga à do estrangeiro que observa com espanto e curiosidade os costumes de uma nação que não é a sua, algo próximo do olhar de Usbek e Rica; e assim por diante. ${ }^{5}$ Mas é sobretudo a proximidade com a sátira de Swift que salta aos olhos e que gostaríamos de sublinhar aqui.

Essa proximidade se mostra, de partida, no uso da alegoria e no simbolismo aí empregado. Trata-se de uma alegoria militar em que o Caminho dos espinhos, no qual todos os soldados iniciam sua trajetória - a despeito de sua vontade, pois o alistamento (batismo) é feito enquanto dormiam -, é a representação alegórica da religião católica. Os caminhantes são lançados no percurso em posse de dois adereços: uma venda que cobre seus olhos, representando sua fé, e um manto branco, representando sua virtude. O príncipe, em cuja direção eles supostamente caminham, deixou-lhes um código militar (escrituras) que contém instruções de como evitar manchas no manto, e limpá-las caso venham a ocorrer; além de instruir também sobre como conservar suas vendas em bom estado.

Segue-se então uma descrição detalhada do corpo militar a serviço do príncipe, desde as hierarquias mais altas (o papa, cardeais e bispos) até as mais baixas (padres, freiras e as

4 Vale lembrar que a sátira não assume necessariamente um tom cômico. Se Horácio consagrou o estilo leve e sutilmente jocoso, Juvenal, por sua vez, celebrizou-se pela ferocidade com que manifestava sua indignação e pelo uso da invectiva.

5 Caberia ainda acrescentar que Diderot se filia aqui ao "tom satírico" desses autores, e que Jaucourt, no verbete $S A T I ́ R I C O$ da Enciclopédia, lista Montaigne entre os autores que, não sendo satiristas em sentido estrito, conferem um estilo satírico aos seus escritos filosóficos (cf. DIDEROT e D’ALEMBERT, 1765, p. 705a). 
diferentes congregações), que guiam os soldados pelo caminho. Um paralelo entre o puritanismo e o jansenismo fica sugerido quando a alegoria apresenta estes últimos como

[i] um secto bastante numeroso de pessoas austeras que aterrorizavam os viajantes por causa da suprema brancura do manto que julgavam necessária, e que saíam gritando nas casas, nos templos, nas ruas e sobre os telhados que o menor pingo de tinta seria uma mancha indelével; [ii] que o sabão do vice-rei e dos governantes não valia nada; [iii] que era preciso retirá-lo diretamente nas lojas do príncipe e encharcá-lo em lágrimas; [iv] que ele o distribuía gratuitamente, mas em pequena quantidade, e que ninguém o desejava; e, [v] como se não houvessem espinhos suficientes no caminho, esses raivosos salpicavam-no com estrepes e cavalos de frisa que o tornavam impraticável. Os viajantes se desesperavam; por toda parte só se ouvia gritos e gemidos (DIDEROT, I, p. 89).

Podemos reconhecer aí (i) o mesmo purismo moral que levara Jack a rasgar seu manto para limpá-lo dos adereços adicionados pelo irmão; (ii) a dissidência em relação à igreja oficial; (iii) a defesa de uma comunicação direta com a divindade e da revelação imediata, tal como a dos inspirados; (iv) a referência à doutrina agostiniana da graça e da predestinação, presente tanto na teologia jansenista quanto na calvinista; e, por fim, (v) os espetáculos do entusiasmo, chegando ao extremo da autoflagelação.

Há, todavia, um limite para a comparação. O passeio do cético não busca oferecer uma explicação do fanatismo comparável à que vimos em $A$ tale of a tub; a alegoria de Diderot é mais descritiva que a de Swift, e não possui, como esta, uma gênese das seitas religiosas dissidentes; além de que o fato de tratar apenas do catolicismo lhe subtrai em alguma medida a dimensão comparativa. Desse modo, o próprio entusiasmo jansenista - e sobretudo dos convulsionários, que, a rigor, seriam a figura mais emblemática do entusiasmo entre os franceses ${ }^{6}$ - aparece diluído no entusiasmo católico ou religioso em geral. Ainda assim, a despeito dessas diferenças, o entusiasmo e o fanatismo são, por assim dizer, elementos estruturantes em $O$ passeio do cético. Isso fica evidente quando a alegoria da religião é articulada às demais alegorias que compõem o texto, isto é, aos caminhos alternativos àquele dos espinhos: o Caminho das castanheiras, sob cujas sombras passeiam os filósofos, e o Caminho das flores, onde estão os libertinos.

O Caminho das castanheiras é referido como um lugar onde o pirrônico abraça o cético, o cético se alegra dos sucessos do ateu, o ateu faz empréstimos ao deísta, o deísta oferece serviços ao espinosista, e onde todas as seitas filosóficas estão "próximas e unidas por laços de amizade" (DIDEROT, 1994, p. 72). Seus habitantes parecem ser, portanto, em tudo distintos dos religiosos. Ainda no Caminho dos espinhos, após uma longa descrição alegórica do mundo judaico-cristão, das hierarquias da igreja, dos livros sagrados, etc, o $\$ 49$ anuncia um diálogo entre um habitante do Caminho das castanheiras, Menipo, e os primeiros semeadores dos espinhos, isto é, os primeiros cristãos. Nesse diálogo, Menipo manifesta certas virtudes filosóficas, expressas em marcas discretas do texto, que anunciam sua fala - por exemplo, quando o narrador relata que "Menipo, que o havia escutado pacientemente e sem interromper, tomou a palavra e continuou" (ibid., p. 98). Essa moderação da fala e respeito ao decoro do diálogo contrastará com a intrepidez dos cristãos. Após escutar pacientemente, portanto,

6 Os convulsionários de Saint-Médard escreveram um dos episódios finais da história do jansenismo. Após seu surgimento a partir da abadia de Port-Royal, em meados do século 17, quando se celebrizou pela adesão de grandes pensadores e personalidades, como Pascal e Arnauld, o jansenismo se difunde e capilariza na sociedade francesa. Pierre Chantin fala num ‘jansenismo teológico', num 'jansenismo político' e, por fim, num 'jansenismo popular' (CHANTIN, 1996). É sob esta última etiqueta que classifica o fenômeno dos convulsionários. Eles surgem a partir da morte do diácono Pâris, da paróquia jansenista de Saint-Médard, em 1727. Os fiéis, crentes de que o religioso operava milagres, passam a frequentar com assiduidade o cemitério anexo à igreja, onde ele havia sido enterrado. Os supostos milagres se realizam ali mesmo, causando grande alvoroço, o que leva as autoridades a fechar o cemitério ao público. A proibição, em vez de esfriar o interesse dos fiéis, faz aumentar o culto ao diácono e dá ensejo às assembleias dos convulsionários, realizadas agora em apartamentos privados, nas quais eles se creem possuídos pelo espírito santo, autoflagelam-se, contorcem-se, profetizam, etc. O fenômeno, porém, marca a decadência do jansenismo, que perde prestígio junto à sociedade francesa à medida que as assembleias de convulsionários se tornam mais escandalosas. 
Menipo toma a palavra e faz uma crítica ao relato dos milagres, apontando sua inverossimilhança. Marcos, que a esta altura se tornou seu interlocutor exclusivo, assume então "o tom de um entusiasta" (DIDEROT, 1994, p. 98); ele grita em vez de falar, e seu discurso agora se assemelha ao dos profetas:

Roma, renuncia a tua incredulidade. Soberba Babilônia, cobre-te de simplicidade; fazei penitência; apressa-te, o tempo é curto, tua queda está próxima, teu império chega ao fim. Que digo, teu império? O universo vai mudar sua face, o filho do homem vai aparecer sobre as nuvens e julgar vivos e mortos. Ele vem; ele bate à porta. Muitos dos que hoje vivem verão a realização dessas coisas (DIDEROT, 1994, p. 98).

Diante desse discurso que se distancia completamente da razoabilidade e beira o delírio, Menipo se retira: o diálogo não é mais possível (§58).

À diferença do caminho das flores, onde se gargalha ruidosamente, no caminho das castanheiras o ridículo dos supersticiosos é objeto de um "gracejo maldoso" (DIDEROT, 1994, p. 85); a gente que aí habita "é naturalmente grave e séria, sem ser taciturna e severa" (ibid., p. 102). Vemos, com isso, que o filósofo está colocado num ponto intermediário de um gradiente que vai da severidade intolerante ao deboche irracional. Enquanto o supersticioso é severo em demasia, a ponto de se irritar diante do riso, e o habitante do caminho das flores, isto é, o libertino, ri em excesso ou convulsivamente, o filósofo zomba, ironiza, satiriza. Existe moderação no tom e uma certa razoabilidade no conteúdo de seu riso, pois ele faz dele um uso crítico.

Raciocinador de profissão, ele gosta de conversar e mesmo de disputar, mas sem aquela acidez e obstinação com a qual se esbravejam delírios entre seus vizinhos. A diversidade de opiniões não altera aqui o comércio da amizade, e não retarda o exercício das virtudes. Ataca-se os adversários sem ódio e, ainda que se os pressione sem restrição, triunfa-se sobre eles sem vaidade (DIDEROT, 1994, p. 102).

A moderação assume importância tal que, mais que uma questão de politesse ou de estilo, ganha, por assim dizer, status de argumento. Assim, mesmo entre os filósofos, entusiasmar-se com as próprias ideias, por melhores que sejam, é já, de certo modo, perder a razão. O razoável se identifica aqui ao moderado, ao ponderado, ao contido, numa palavra, à ausência de entusiasmo, seja ele referido à religião ou à própria filosofia.

A crítica ao entusiasmo se faz então por um movimento do diálogo que empurra o entusiasta para o lugar do ridículo, como ocorrerá com o ateu, que se exaspera e provoca o riso dos outros filósofos. Apegar-se ferrenhamente a uma posição é ridículo, coloca-nos numa situação cômica. $O$ texto de $O$ passeio do cético produz assim um jogo de recuos, em que cada debatedor, ou cada posição em debate, vai se tornando ridícula, ao se crer dona da verdade; elas se afirmam, com mais ou menos arrogância, e são em seguida destronadas de sua pretensa autoridade. No ponto final desse jogo de recuos, só o narrador - que passeia sem compromisso por entre os sistemas -, se salva do ridículo. Há um deslizamento, de recuo em recuo, que faz a ironia da narrativa.

Se não há propriamente uma filosofia, pois não há adesão a nenhum sistema, há contudo a afirmação de uma atitude filosófica: o ensinamento d'O Passeio é um certo recuo crítico, uma refração, uma inaderência que, embora do ponto de vista teórico se revele essencialmente negativo, em termos práticos remete à ideia de um ethos democrático e tolerante.

\section{Epílogo}

A ideia de que o entusiasmo, e com ele, o fanatismo, não é o privilégio dos religiosos fervorosos, mas um perigo que ronda também a filosofia está sugerida em $O$ passeio do cético. 
Para encerrar nosso percurso, todavia, gostaríamos de recuperar brevemente um texto em que Diderot tematiza explicitamente a questão, promovendo uma curiosa inversão.

O diálogo Cinqmars et Derville (1760) passa facilmente batido como uma obra de circunstância - as últimas frases revelam seu verdadeiro alvo: Palissot ${ }^{7}$ - e por isso desimportante; cremos, contudo, que aporta uma contribuição interessante. Nele vemos Cinqmars, que em seguida reconheceremos como o porta-voz do filósofo, saindo apressado e contrafeito de um banquete. Derville sai em seu encalço, e busca saber o porquê da retirada repentina do amigo. Cinqmars então explica que, à parte outros motivos menores, enfureceu-se sobretudo com o relato, feito por um dos convivas, ${ }^{8}$ de uma assembleia de convulsionários, contrafazendo os gestos desses entusiastas, e provocando gargalhadas dos demais, inclusive de Derville.

Trata-se, segundo Cinqmars, de um riso irresponsável e cruel, pois se dirige contra pessoas que, num estado patológico que as coloca momentaneamente fora de si, colocam suas próprias vidas e as dos outros em risco. "Como é possível", diz ele a Derville, "que você seja afetado apenas pelo ridículo dessa pantomima indecente e não perceba que o delírio e a alienação dessas cabeças fanáticas as tornam cruéis e homicidas contra si mesmas e seus semelhantes?" (DIDEROT, 1970, p. 754). Derville reconhece a correção das observações de Cinqmars, mas objeta que, afinal, são eles mesmos, os convulsionários, que escolhem tomar parte nesses horrores, ao que Cinqmars responde:

que seja. Mas a causa dessa escolha é absurda!... Ela não está ligada a um transtorno dos órgãos, e assim à fraqueza de nossa natureza?... Uma fibra mais ou menos tensionada... Saiba que uma de vossas gargalhadas imoderadas poderia vos tornar tão deplorável... ou tão cômico quanto eles (DIDEROT, 1970, p. 755).

Diderot inverte os lugares e mostra Du Doyer de Gastel, colaborador da Encyclopédie e a justo título um dos philosophes, como um fanático, rindo compulsivamente; ou talvez pudéssemos dizer: convulsivamente, à mercê de seu diafragma. Nesse momento, ele deixa de ser filósofo e pode passar do caminho das castanheiras ao das flores, onde se ri "à gorge déployée" (DIDEROT, 1994, p. 85); ou pior: se tornar convulsionário, fanático.

Após essas considerações, feitas em tom de censura, a rubrica do texto indica pela primeira vez Cinqmars "sorrindo"; é que Derville reconheceu já a tolice do riso que compartilhara à mesa de Versac (Du Doyer de Gastel), e se coloca agora numa disposição aberta à reflexão: "Admito", diz ele, "que jamais havia refletido direito sobre o riso e suas causas. Há tantas..." (DIDEROT, 1970, p. 756). Cinqmars, que conseguiu restituir ao assunto a gravidade que lhe é devida, e já antevendo talvez a 'conversão' de Derville às suas ideias, pode agora se permitir a disposição bem-humorada indispensável à reflexão filosófica. Reencontramos neste ponto Shaftesbury, cuja teoria do sentimento moral está pressuposta em todo o percurso de Diderot até aqui. ${ }^{9}$

Cinqmars avança então uma teoria do riso, ou do cômico: "é sempre a ideia de defeito [défaut] que excita em nós o riso; defeito ou nas ideias, ou na expressão, ou na pessoa que age, ou que fala, ou que é o objeto da conversa" (ibid., p. 756); com uma condição: "toda vez que a ideia

\footnotetext{
7 Ao fim do diálogo, os dois interlocutores se despedem e Derville, que havia mencionado seu interesse em assistir a uma peça naquela noite, revela que desistiu do intento após a conversa. A peça em questão é Les philosophes, de Charles Palissot, encenada em 1760, mesmo ano da composição do diálogo de Diderot. Nela, Palissot satiriza cruelmente os filósofos e enciclopedistas, e Diderot em especial, não se furtando a ataques pessoais. $O$ tom da resposta de Diderot em Cinqmars e Derville é sério, inclusive censurando o tipo de riso que ataca a pessoa e não a ideia. Em O sobrinho de Rameau, porém, o contra-ataque diderotiano se valerá do humor para satirizar Palissot como um dos sacripantas do bando de Rameau.

8 O conviva que narrou e contrafez os convulsionários é Du Doyer de Gastel, que teve seu relato de uma dessas assembleias de convulsionários publicado na Correspondance Littéraire, editada por Melchior Grimm. No diálogo de Diderot ele é nomeado como Versac.

9 A propósito da vantagem de uma disposição bem-humorada para tratar de assuntos religiosos, ver Shaftesbury, 2000, sect. 3, pp. 12-17.
} 
de perigo não se encontre aí junta; pois ela impede o riso de todos aqueles que atingiram a idade da razão" (ibid., p. 757).

Fica assim descrito um percurso de modulação do riso, que equivale a um processo de reflexão em que o próprio filósofo, enquanto aquele que ri, é colocado em questão; esse movimento, ensaiado pela sátira inglesa, é, por fim, tematizado e se torna consciente pelas mãos de Diderot, para quem "o riso é a pedra de toque do gosto, da justiça e da bondade" (ibid., p. 756). 


\section{Referências}

BURTON, Robert. The Anatomy of Melancholy. Anboco, 2016.

CHANTIN, Jean-Pierre. Le jansénisme. Entre hérésie imaginaire et résistance catholique (XVII - XIX ${ }^{e}$ siècle). Paris: Les Éditions du Cerf, 1996.

DIDEROT, D. Oeuvres I. Paris: Robert Laffont, 1994.

DIDEROT, D. Euvres complètes 4. Paris: Le Club Français du Livre, 1970.

DIDEROT, D. Diderot Obras II. São Paulo: Perspectiva, 2000.

DIDEROT e D'ALEMBERT. Encyclopédie, ou dictionnaire raisonné des sciences, des arts et des métiers. Vol. XIV (1765). Disponível em: http://enccre.academiesciences.fr/encyclopedie/article/v14-2417-0/. Consultado pela última vez em 03 de agosto de 2021. JONSON, Ben. The Selected Plays of Ben Jonson Volume 2. Cambridge University Press, 1989. MORE, H. A collection of several philosophical writings of Dr. Henry More. 1662. Disponível em: https://gallica.bnf.fr. Consultado pela última vez em 03 de agosto de 2021.

SHAFTESBURY. Characteristics of men, manners, opinions, times. Cambridge University Press, 2000 .

SWIFT, J. The basic writings of Jonathan Swift. Nova Iorque: The Modern Library, 2002. WEBSTER, C. M. Swift and Some Earlier Satirists of Puritan Enthusiasm. PMLA, vol. 48, no. 4, 1933, pp. 1141-1153. Disponível em: www.jstor.org/stable/458201. Consultado pela última vez em 03 de agosto de 2021.

Autor(a) para correspondência / Corresponding author: Felipe Aquino de Cordova. felipeacordova@gmail.com 